\title{
Improving hand hygiene: thinking outside the bottle
}

\author{
D Harkin*, M-L McLaws \\ From International Conference on Prevention \& Infection Control (ICPIC 2011) \\ Geneva, Switzerland. 29 June - 2 July 2011
}

\section{Introduction / objectives}

Hand hygiene is an integral aspect of infection control. The provision of Alcohol Based Hand Rub (ABHR) gel at patient bedsides has made effective hand hygiene (HH) more convenient for Health Care Workers (HCWs) by overcoming two of the main 'barriers' to $\mathrm{HH}$ - time and distance to sinks, by placing the bottles at the point of patient care. The ABHR bottles, being novel, ubiquitous and usually brightly coloured, were originally very effective in cuing HCWs to observe $\mathrm{HH}$. In the years since their introduction, these attributes have not translated into $\mathrm{HH}$ rates much above $60 \%$. This suggests that AHR bottles may not have retained the cue to memory they originally held.

\section{Methods}

A series of direct observations and interviews with HCW s have suggested that the ABHRbottles, in the modern, busy patient environment are not as noticeable as they once were. Even if they are brightly coloured bottles, HCWs have become inured to their presence. We drew upon the practice of commercial manufacturers of similar products- like liquid soap and shampoo. They constantly modify and refresh the external attributes of their products to maintain their profile in the public eye. We developed a study to test whether such an approach could have the same effect in a clinical setting. We developed a study which involves modifying the external attributes of the ABHR bottles to refresh them in the eyes of HCWs- and test whether they can improve $\mathrm{HH}$ rates as a result of these modifications.In addition to measuring $\mathrm{HH}$ compliance rates, it will have a qualitative aspesct to gauge the perceptions of HCWs taking part in the study.

School of Public Health and Community Medicine, University of New South Wales, Kensington, Australia

\section{Results}

The study will begin at a Sydney teaching hospital in May 2011.

\section{Conclusion}

This study will determine whether this novel approach can assist and support HCWs in complying with $\mathrm{HH}$ protocols.

\section{Disclosure of interest}

None declared.

Published: 29 June 2011

\section{doi:10.1186/1753-6561-5-S6-P116}

Cite this article as: Harkin and McLaws: Improving hand hygiene:

thinking outside the bottle. BMC Proceedings 2011 5(Suppl 6):P116.
Submit your next manuscript to BioMed Central and take full advantage of:

- Convenient online submission

- Thorough peer review

- No space constraints or color figure charges

- Immediate publication on acceptance

- Inclusion in PubMed, CAS, Scopus and Google Scholar

- Research which is freely available for redistribution
() Biomed Central

\section{Biomed Central}

